Table 1

f Scores, Response Rates, and Reinforcements for Individual Si

\begin{tabular}{|c|c|c|c|c|c|c|}
\hline $\mathrm{S}$ & GRP & $\begin{array}{l}\text { Median } \\
\text { Base } \\
\text { linc } \\
\text { i }\end{array}$ & $\begin{array}{l}\text { Median } \\
\text { lest } \\
t\end{array}$ & $\begin{array}{l}\text { Hean } \\
\text { Response } \\
\text { Rate in } \\
\text { TO }\end{array}$ & $\begin{array}{c}\text { Mean } \\
\text { Ropome } \\
\text { Rate in } \\
\text { "Normal lime" }\end{array}$ & $\begin{array}{l}\text { Total } \\
\text { Reinfores- } \\
\text { ment } \\
\text { Obtained }\end{array}$ \\
\hline 1 & 1: & 93 & 100 & 0.42 & 46.9 & 147 \\
\hline 2 & $\mathrm{I}:$ & 118 & 110 & 1.85 & 41.2 & 152 \\
\hline 3 & $1:$ & 99 & 95 & 0.30 & 37.6 & 148 \\
\hline 4 & 1: & 100 & 111 & 0.43 & 33.5 & 148 \\
\hline 5 & $1:$ & 100 & 110 & 6.13 & 60.4 & 139 \\
\hline 6 & $1:$ & 102 & 100 & 0.43 & 17.4 & 146 \\
\hline 7 & $\mathrm{R}$ & 131 & 150 & 5.03 & 6.3 & 140 \\
\hline 8 & $\mathrm{R}$ & 111 & 118 & 4.35 & 47.2 & 144 \\
\hline 9 & $\mathrm{R}$ & 78 & 104 & 5.05 & 21.1 & 139 \\
\hline 10 & $\mathrm{R}$ & 100 & 105 & 10.65 & 51.7 & 157 \\
\hline 11 & $\mathrm{R}$ & 102 & 104 & 85.38 & 139.5 & 160 \\
\hline 12 & $\mathrm{R}$ & 103 & 102 & 33.73 & 91.2 & 160 \\
\hline
\end{tabular}

every PCS/CS presentation for each S; the median f scores during baseline and test, again for each $\mathrm{S}$, appear in Table 1 .

Median f scores in baseline and test were compared for all $12 \mathrm{Ss}$ using a Wilcoxon t test (Siegel, 1956) since inspection showed that the data was not normally distributed. There was a significant facilitation during the CS under the experimental, TO, condition $(\mathrm{p}<.05$, $t=15.5$, one-tailed). However, the difference between the baseline and test scores for the $F$ group alone was not significant $(p>05, t=7)$, whereas the facilitatory effect remained significant for the $\mathrm{R}$ group taken alone $(\mathrm{p}<.05,1=1)$. It was concluded that the effect of the CS on response rate was largely neutralized by the effect of full instructions. Also, since all Ss obtained virtually the maxinum number of points (see Table 1), the effect was unlikely to be due to adventitious reinforcement.

Mean response rates during periods where TO was not in effect (normal time) were compared for $F$ and $R$ groups using a Mann-Whitney U test (Siegel, 1956), but no significant difference was found $(\mathrm{U}=13, \mathrm{p}>.05)$. However, using the same test, the rate during TO for the $\mathrm{R}$ group was significantly higher than that for the $F$ group receiving instructions that discriminated TO from normal time $(\mathrm{U}=3$, $\mathrm{p}<.01)$. Despite this, comparing mean TO and normal time rates for both groups separately yielded significantly lower rates in TO ( $\mathrm{F}$ and $\mathrm{R}$ groups: $\mathrm{t}=0, \mathrm{p}<.05)$. For $\mathrm{Ss}$ in the $\mathrm{F}$ group, cumulative records were virtually flat from the start of the session, whereas $\mathrm{Ss}$ in the $\mathrm{R}$ group gradually reduced their rates as the session progressed. Differences in this group between total responses in the first and last six TO periods were found to be significant $(\mathrm{t}=0, \mathrm{p}<.025$, one-tailed $)$.

\section{DISCUSSION}

The results partially confirm the finding of Trenholme et al that a facilitatory effect during a CS can be obtained using TO as a US in a CER paradigm with human Ss. In the comparatively compressed experimental design used in the present study, the effect was found to be small but significant. Further, it was also found to be present where Ss did not increase their probability of reinforcement by responding at a higher rate. In contradiction to the earlier finding, instructions establishing the discrimination of TO had the effect of neutralizing the facilitation found when instructions were omitted, although noninstructed Ss had clearly shown evidence of learning the discrimination by the end of the session.

Analysis showed that (1) where the TO discrimination was immediately learned, as for $\mathrm{F}$ group Ss, there was no effect; and (2) Ss in the $R$ group had learned the discrimination within 24 presentations of TO. It may therefore be concluded that the CS facilitatory effect is transitory in quality of speech in voting for leaders. inuman Ss using small amounts of money as a reinforcer. Trenholme et al, however, have shown a relatively stable effect.

If the immediate effect of a CS signaling TO, regardless of instructions, is facilitatory and if in turn this faster response rate leads to increased reinforcement density, the effect may be fortuitously maintained. In the present study, where this did not occur, the effect was relatively transitory, producing an insignificant effect in instructed Ss and a small, but significant, effect in Ss receiving no instructions.

At present it would scem unlikely that. with human Ss working at a simple task, a durable emotional effect could be obtained. This is especially true where only small monetary rewards, mildly aversive unconditioned stimuli and unrealistic experimental situations are employed.

\section{REFERENCFS}

FERSTER, C. B. Control of behavior in chimpanzees and pigeons by time out from positive reinforcement. Psychological Monographs, 1958, 72(8, Whole No. 461).

LEITENBERG, $\mathrm{H}$. Conditioned acceleration and conditioned suppression in pigeons. Journal of the Experimental Analysis of Behavior. 1966. 9. 205-212.

LEITENBERG, H., BERTSCH, G., \& COUGLIN, R. "Time-out from positive reinforcement" as the UCS in a CER paradigm with rats. Psychonomic Science, 1968, 13, 3-4.

RESCORLA, R. Pavlovian conditioning and its proper control procedures. Psychological Review, 1967, 74, 71-80.

SIEGEL, S. Nonparametric statistics. New York: McGraw-Hill, 1956.

TRENHOLME, I., BARON, A., \& KAUFMAN, A. Effects of signaled time-out from and loss of monetary reinforcement on human operant behavior. Psychonomic Science, 1969. 15 295-296.

\title{
Leadership selection under differing feedback conditions
}

\author{
CABOT L. JAFFEE, ${ }^{*}$ STEVEN A. RICHARDS, ${ }^{* *}$ and GERALD W. McLAUGHLIN ${ }^{\dagger}$ \\ University of Tennessee, Knoxville, Tenn. 37916
}

Under two differing feedback conditions (specific and nonspecific) leadership voting within small groups was analyzed. It was found that modifying the percentage of reinforcement to different Ss influenced voting behavior significantly, and that Ss in the two treatment conditions did not differ in their ability to match votes with reinforcements. It was felt that Ss respond more rapidly to duration of speech rather than 
Table 1

Number of Leadership Votes Under Differing Reinforcement and Feedback Conditions

\begin{tabular}{|c|c|c|c|c|c|c|c|c|}
\hline \multirow[b]{2}{*}{ Subject } & \multicolumn{2}{|c|}{ Period 1} & \multicolumn{2}{|c|}{ Period 2} & \multicolumn{2}{|c|}{ Period 3} & \multirow[b]{2}{*}{$\mathrm{F}$} & \multirow[b]{2}{*}{$\mathrm{p}$} \\
\hline & Mean & SD & Mean & SD & Mean & $\mathrm{SD}$ & & \\
\hline \multicolumn{9}{|c|}{ Specific Feedback ( $N=17$ Groups) } \\
\hline 599 & 9.20 & 1.16 & $11.00^{*}$ & 1.34 & 11.50 & 2.06 & 5.68 & $\mathrm{p}<.01$ \\
\hline 555 & 9.20 & 1.88 & $\overline{8.70}$ & 2.60 & $\overline{10.10}$ & 1.97 & n.s. & \\
\hline 511 & 11.60 & 1.56 & 10.30 & 1.55 & 8.40 & 1.96 & 16.89 & $\mathrm{p}<.005$ \\
\hline \multicolumn{9}{|c|}{ No Feedback ( $\mathrm{N}=10$ Groups $)$} \\
\hline 599 & 10.11 & 1.32 & 11.11 & 2.17 & 12.70 & 1.83 & 7.74 & $\mathrm{p}<.005$ \\
\hline 555 & $\overline{9} . \overline{3}$ & 1.13 & 9.76 & 2.17 & 9.70 & 2.05 & n.s. & \\
\hline 511 & 10.54 & 2.90 & 9.13 & 2.65 & 7.60 & 2.40 & 20.5 & $\mathrm{p}<.005$ \\
\hline
\end{tabular}

*Means underlined for the same $S$ are not significantly different from each other at .05 level.

Jaffee \& Lucas (1969) have found that Ss in a leaderless group discussion will attend to the irrelevant cue of duration of speech rather than to the more relevant cue of quality of speech (number of reinforcements for correct answers) when selecting members of the group "best able to lead them in future discussions of problems." In fact, in the study cited above, when an experimental confederate (stooge) was directed to respond with either high or low durations of speech and number of reinforcements to this Ss were modified inversely (high speech, low correctness vs low speech, high correctness, the naive group members used the duration of speech variable significantly more often in choosing a leader. One question that follows readily from these results centers around the determination of Ss' knowledge of the reinforcement schedules of the stooge. Did naive Ss respond to duration of speech because they felt that it was the more important aspect of the two contradictory behaviors or did they not have a clear picture of the schedules of reinforcement? There is some evidence from the Jaffee \& Lucas (1969) study and a later one by Lucas \& Jaffee (1969) that at least with some Ss the perception of actual reinforcement schedules was accurate. This experiment was designed to examine leadership selection when Ss were made aware of the number of correct responses (reinforcements) vs when they were given no specific information relative to this variable.

\section{SUBJECTS}

Eighty undergraduate females from introductory psychology classes at the University of Tennessee were used to form 27 groups of three persons each.

\section{APPARATUS}

The apparatus used is the same as that

*Reprints may be obtained from the first author at the Department of Industrial Management, University of Tennessee, Knoxville, Tenn 37916

**Presently Assistant Professor of Psychology San Diego State College, San Diego, Calif. 92115.

$\leftarrow$ Presently assigned to the United States Military Academy at West Point. described in greater detail in the Jaffee \& Lucas (1969) study. Generally it consisted of a concept-formation board with 36 lights and differing geometric figures used to provide the stimuli for discussion and a means of reinforcing particular Ss (by making their choice of a concept light the correct one). In front of each $S$ was a small box containing a leadership selection switch, by means of which all Ss could vote for a leader on each trial, and a dial for indicating a choice of the correct light.

\section{PROCEDURE}

The Ss were told they were involved in a problem-solving task and the techniques used would be observed and recorded from behind the one-way glass by $E$. When the light designated as the select-leader light came on, they were to vote for a leader for that trial. The leader was to announce the group's choice and should be the individual most qualified to do so. They could not vote for themselves. If each group member received one vote, a random-order schedule of tie-breaking numbers was used. The $\mathrm{E}$ would indicate who the selected leader was by lights at the top of the concept-formation board. If light 1 went on, $\mathrm{S} 1$ was the leader for that trial, etc. Four lights would then be flashed on the concept-formation board. Ss' task was to figure out what the next light to come on would be. They were told the concepts could be based on the sequence of numbers, the geometric figures themselves, or the positioning of the lights in space. The light selected would then complete the number sequence, the figure pattern, or the spatial pattern that lights made. Then only the leader elected for the trial made a decision for the group by means of a dial, and she was publicly reinforced or not reinforced by means of lights above the concept board. The selected leader light went on again, and the procedure was repeated for 30 trials. During this time all Ss were reinforced at a rate of being right $50 \%$ of the time, regardless of their answers, according to the predetermined randomized reinforcement schedule.

After 30 trials, the reinforcement schedules were changed. One $S$ had her reinforcement schedule changed to .9 meaning her choices would be correct $90 \%$ of the time regardless of what she said, while another $\mathrm{S}$ was now reinforced at $.1:$ a third $S$ was reinforced at a constant .5 for an additional 30 trials. At the conclusion of this period, 17 of the groups were given feedback as to the number of correct responses by each $\mathrm{S}$ in the group. while 10 of the groups proceeded into the final period of 30 trials without this specific information. All groups were then treated precisely as they had been during the second period and the reinforcement schedule was continued for another 30 trials.

\section{RESULTS AND DISCUSSION}

The results may be seen in Table 1 , and were rather interesting. ${ }^{1}$ The two conditions produced almost identical results in terms of voting behavior. No significant differences at the .05 level were found in comparing, by t tests, the means of Period 2 and 3 feedback with the means of Period 2 and 3 no-feedback. Both the specific feedback condition and the nonspecific feedback condition produced voting behavior that indicated $\mathrm{Ss}$ were indeed tracking the reward contingencies quite accurately even when not told specifically what they were. Furthermore, voting behavior was quite sensitive to reward contingencies, and Ss appeared to modify votes for the leader in a direction of the changes in reward. Since Ss were not allowed an opportunity to influence other group members by duration of speech it appears safe to say that voting results were a function of equally good tracking on the part of Ss in both conditions. This appears to indicate that Ss in the Jaffee and Lucas experiment were able to differentiate reward contingencies and schedules, but were more influenced by sheer duration of speech under the conditions of that experiment.

\section{REFERENCES}

JAFFEE, C. L., \& LUCAS, R. L. Effects of rates of talking and correctness of decisions in leadership choices in small groups. Journal of Social Psychology, 1969, 79, 247-254.

LUCAS, R. L., \& JAFFEE, C. L. The effects of high-rate talkers on voting behavior in the leaderless group problem-solving situation. Psychological Reports, 1969, 25, 471-477. NOTES

1. A repeated-measures analysis of variance indicated significant $F s$ for $S s$ whose reinforcement schedules were changed, 599 and 511 , and no significant changes in the mean number of votes for $S s$ whose reinforcement schedules were not changed (the $555 \mathrm{Ss}$ ). Further analysis of the means by Duncan's multiple range test showed that most of the means were significantly different from each other at the .05 level. Those that were not statistically different were underlined. (See Table 1.) It can be noted that all Period 3 means are significantly different from Period 1 means in the predicted direction. 